\title{
La creación del Centro Valenciano de Estudios y Conservación del Patrimonio del Cómic constata el valor de la historieta
}

\begin{abstract}
La ciudad de Valencia contará con el nuevo Centro de Estudios y Conservación del Cómic. El Ayuntamiento de la ciudad y el Vicerrectorado de Cultura de la Universitat de Valencia (UV), a través de su Aula del Cómic, colaborarán en la gestión y coordinación de las actividades del futuro espacio cultural así como en la dotación y ampliación de las colecciones. Es el primer centro público en España de estas características, donde están previstas labores de archivo y conservación del patrimonio cultural y creativo del cómic, así como trabajos de investigación, formación y divulgación.
\end{abstract}

Álvaro M. Pons Moreno | Cátedra de Estudios del Cómic, Fundación SM-Universitat de València

URL de la contribución <http://www.iaph.es/revistaph/index.php/revistaph/article/view/4934>

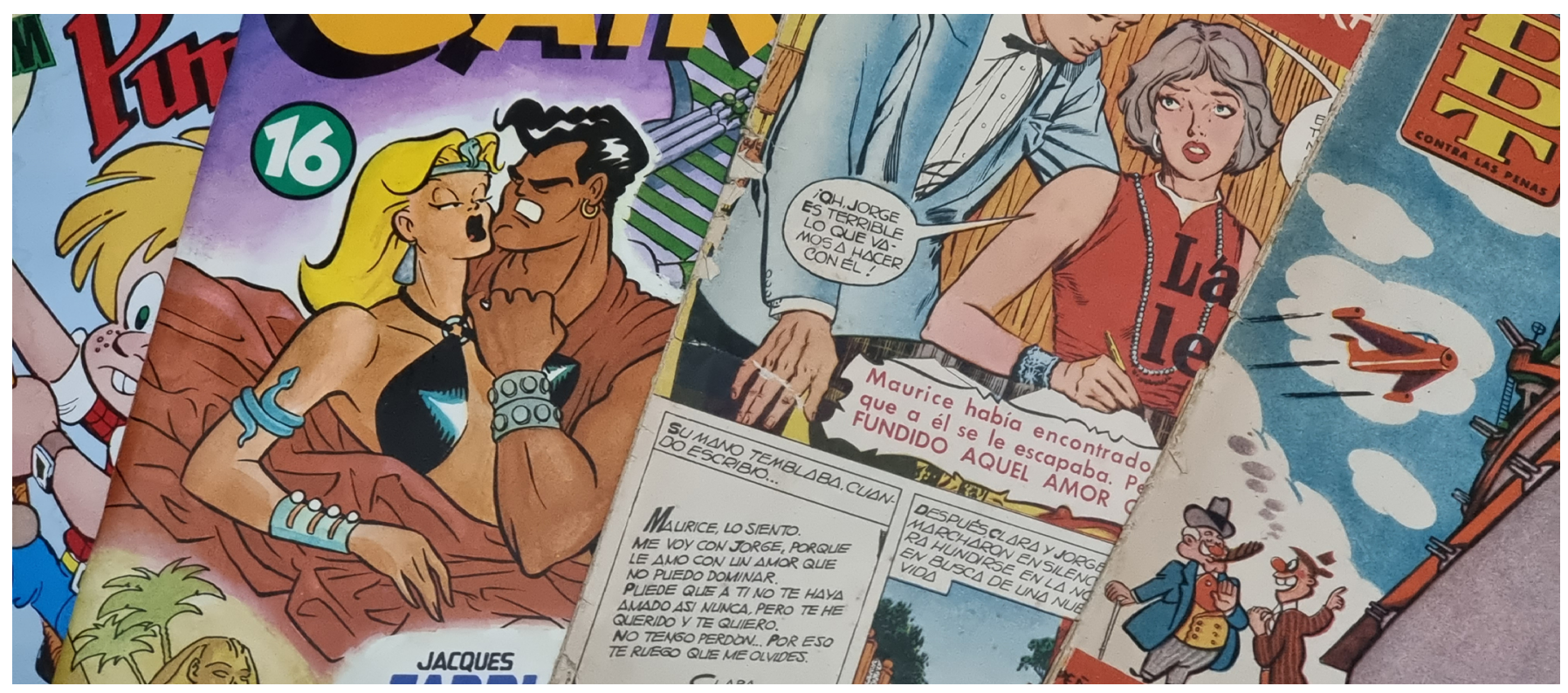

El cómic, fuente historiográfica de primera magnitud para el estudio de nuestra pasado | foto Álvaro M. Pons

Durante los años 50, por la revista El DDT contra las penas, publicada por la editorial Bruguera, desfiló un auténtico catálogo de tipos y formas de la sociedad de la posguerra franquista: empresarios estraperlistas, duras suegras que hacían la vida imposible de los yernos que tenían que vivir en la casa familiar, pícaros aprovechados de la buena voluntad de sus vecinos, "influencers" avant la lettre capaces de sortear las aguas de las corruptelas públicas, reprimidos sexuales incapaces de mirar a una mujer, familias de padre pluriempleado o incluso moder- nas parejas sin hijos que atentaban contra el mandato de la familia numerosa del régimen (Pons Moreno 2014). Todo un retrato sociológico que era imposible encontrar en ninguna otra expresión artística: la censura reprimía cualquier intento de alejamiento del discurso oficialista del franquismo pero, sorprendentemente, se olvidó de mirar los contenidos de los inocentes tebeos más allá de las cautelas carnales. El cómic se constituye en una fuente historiográfica de primera magnitud para el estudio de nuestra pasado (Gual 2013), tanto de forma directa 
como indirecta (Pons Moreno 2006), creando una argumentación añadida a la de su importancia como medio artístico y cultural. Superados ya los prejuicios que marcaban al noveno arte como un medio de segunda categoría y de proyección únicamente infantil, el cómic se establece como un lenguaje que se desprende de las rémoras del pasado para mirar el futuro con un potencial inabarcable. Sin embargo, todo ese pasado de persecución continuada ha dejado no pocas consecuencias: el cómic afronta el siglo XXI con un despertar creativo absolutamente deslumbrante, pero con el peligro de olvidar por completo su legado. La negación continuada del cómic como una forma artística de importancia ha desterrado la creación de historietas a un ámbito de producción industrial durante décadas, que no solo rebajaba la

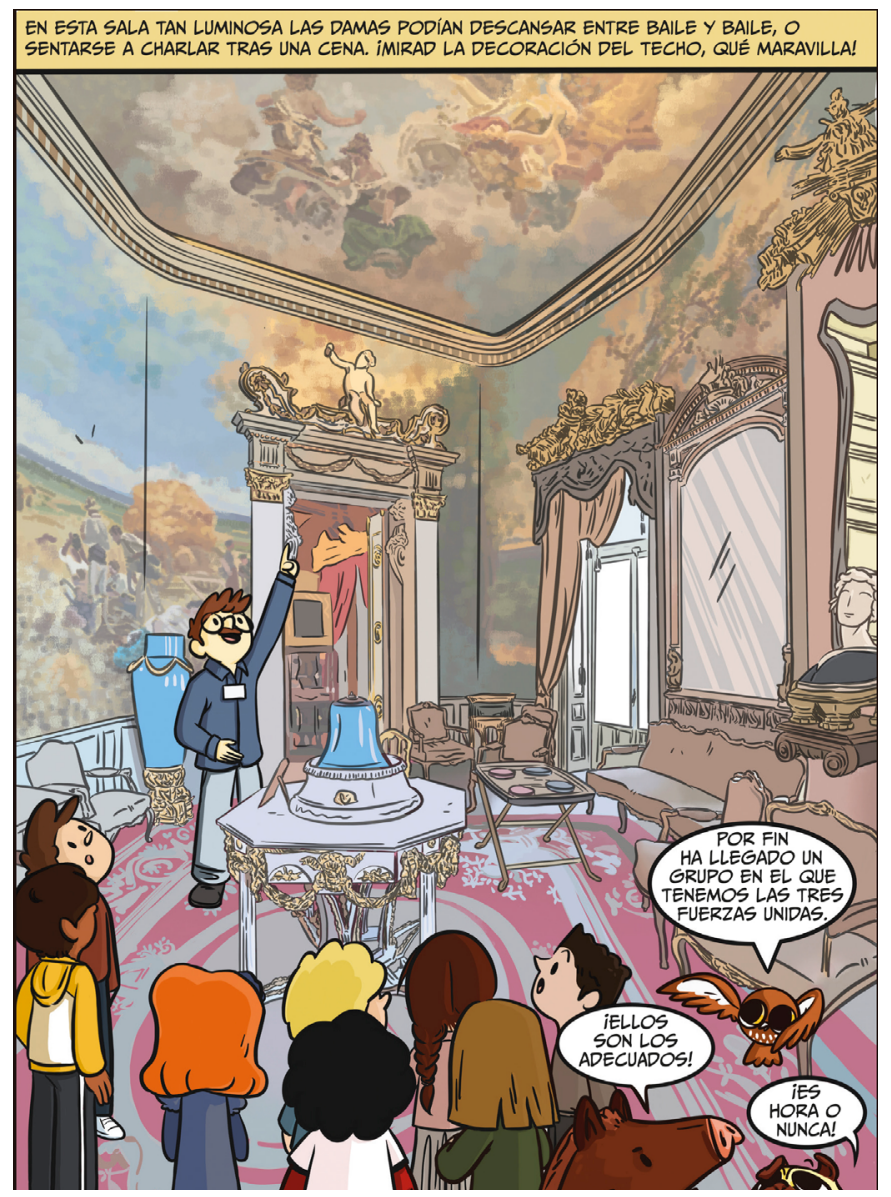

Cómic para niños Aventura en el Museo Cerralbo (2020). Autoras Cecilia Casas y Cristina Rodríguez-Acosta | foto Fundación Museo Cerralbo consideración de los autores y autoras a los de meros asalariados de un eficaz tejido industrial, sino a la propia creación a la categoría de producto. Todo el desarrollo del proceso creativo se reduce a simple material fungible para un arte diseñado para el consumo y el "usar y tirar".

Aunque la reivindicación del tebeo como forma artística ya se inicia en los años 60 del siglo XX y adquiere formas académicas en los 70 (Boltanski 1975), no será hasta bien entrado el siglo XXI que las instituciones comiencen a interesarse por incorporar al cómic a la normalidad cultural y académica. En España hemos visto cómo, en las dos últimas décadas, la consideración del cómic ha sufrido un cambio radical que ha llevado a su reconocimiento por las instancias políticas (con el hito de la instauración del Premio Nacional de Cómic), su incorporación al discurso expositivo de los principales centros museísticos del país (como el IVAM de València, el Museo Nacional Centro de Arte Reina Sofía o el Museu Nacional d'Art de Catalunya) o el interés desde las universidades, con la apertura de aulas de cómic (en Murcia, Alicante o Valencia), la instauración de cátedras institucionales dedicadas al cómic o la consolidación de líneas de investigación alrededor de la historieta que ya se han plasmado en un importante número de tesis doctorales (Gracia Lana 2020). Es interesante señalar cómo esta introducción del cómic en el ámbito museístico no solo se ha dado desde la perspectiva del cómic como patrimonio físico, sino de las posibilidades didácticas que permite la historieta en la divulgación del patrimonio cultural. Son muchas las instituciones que están apostando de forma activa por el uso del lenguaje del cómic para hacer llegar al gran público la riqueza patrimonial y artística, ya desde una perspectiva docente (como puede ser por ejemplo la serie Historia del Arte en Cómic, de Pedro Cifuentes, publicada por la editorial Despertaferro) o incluso puramente ficcional (Flinn 2013).

Sin embargo, este cambio tiene cimientos endebles: todos estos movimientos requieren, necesariamente, acceder al patrimonio de nuestra historieta. Una condición difícil de cumplir en la actualidad ya que, pese a que algunas bibliotecas mantienen importantes colecciones de cómic, la gran mayoría del tebeo publicado en España en el último siglo es casi inaccesible. El mantenimiento 


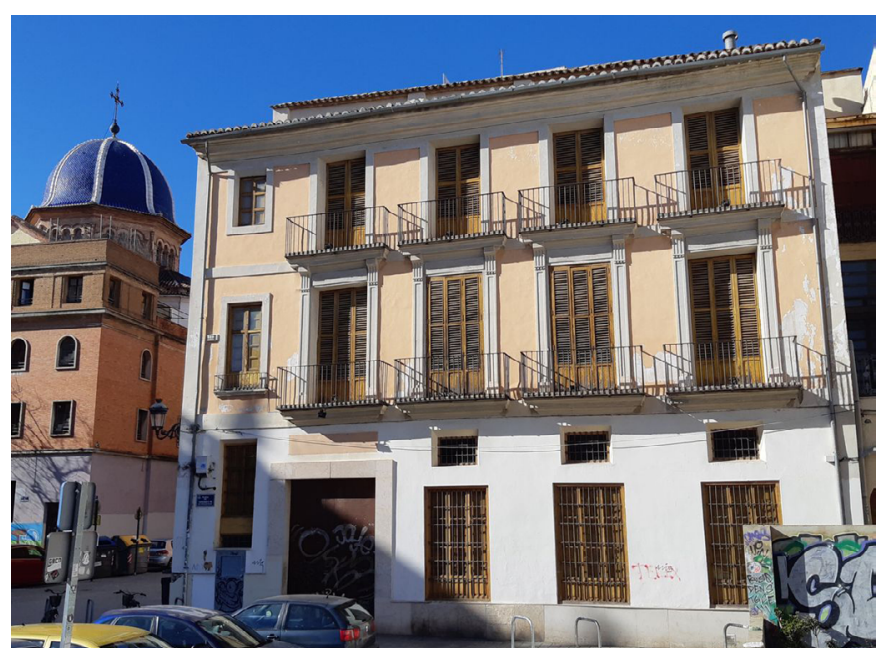

El antiguo Centro Excursionista será la sede del Centro Valenciano de Estudios y Conservación del Patrimonio del Cómic | foto Ayuntamiento de Valencia

del patrimonio español de la historieta se ha producido gracias a coleccionistas que guardan con esmero ejemplares casi incunables o los originales que tenían como destino la destrucción. Iniciativas privadas de catalogación, de carácter tan voluntarista como titánico como la que lleva a cabo la Asociación Cultural Tebeosfera, nos hablan de cientos de miles de cómics que, de no mediar acciones inmediatas, pueden perderse y olvidarse por completo, como ya hemos visto en otros países.

Una situación casi desesperada que hace indispensable la creación de instituciones que coordinen los esfuerzos de recuperación y conservación del patrimonio de la historieta, que sirvan de espacio además para la promoción activa de la investigación y el estudio de un arte con unas potencialidades que rebasan lo histórico.

La creación del Centro Valenciano de Estudios y Conservación del Patrimonio del Cómic es un paso fundamental en esta línea. Promovido por la Concejalía de Acción Cultural del Ayuntamiento de València y el vicerrectorado de Cultura de la Universitat de València, tendrá como función principal el impulso de la investigación y el trabajo sobre el patrimonio del cómic español. Pero el centro no será solo un contenedor de todo esa riqueza cultural; actuará como un dinamizador activo de sus fondos a través de tres líneas fundamentales de trabajo: en primer lugar, la catalogación, conservación, digitaliza- ción y restauración de esos fondos. En segundo lugar, la promoción de la investigación académica en conjunción con las universidades y centros de investigación públicos y privados tanto nacionales como internacionales. $\mathrm{Y}$, por último, retornando esa investigación a la sociedad a través de la divulgación y la formación, actuando como catalizador de muestras, exposiciones, charlas, cursos o jornadas que exploren el pasado, presente y futuro de la historieta y la riqueza autoral de nuestro país.

Para ello, el centro no solo debe tener una amplia colección de fondos, que deberán ser obtenidos mediante compras, donaciones, cesiones o comodatos de instituciones y particulares, sino que debe actuar de coordinador y localizador de los fondos de cómic que existan en el país, tanto en manos públicas como privadas. Una tarea que necesitará de la colaboración activa de todos los actores del cómic: asociaciones, editoriales, colectivos de autores y autoras, críticos o librerías son engranajes fundamentales de un proyecto que tiene como fin la reivindicación del patrimonio de la historieta española.

\section{BIBLIOGRAFÍA}

- Boltanski, L. (1975) La constitution du champ de la bande dessinée. En: Actes de la Recherche en Sciences Sociales, vol. 1, n. $^{\circ} 1$, pp. 37-59

- Flinn, M. (2013) High Comics Art The Louvre and the Bande Dessinée. European Comic Art, vol. 6, n. ${ }^{\circ}$ 2, pp. 69-94

- Gracia Lana, J.A. (2020) La tesis doctoral como baremo de los estudios recientes sobre cómic y humor gráfico en España (1996-2016). Tebeosfera: Cultura Gráfica, n. ${ }^{0} 13$. Disponible en: https://www.tebeosfera.com/documentos/la_te sis_doctoral_como_baremo_de_los_estudios_recientes_so bre_comic_y_humōr_grafico_en_espana_1996-2016.html [Consulta: 01/04/2021]

- Gual, O. (2013) Viñetas de posguerra: Los cómics como fuente para el estudio de la historia. Valencia: Servei de Publicacions de la Universitat de València

- Pons Moreno, A.M. (2006) Unha arte democrática: o tebeo como espello da sociedade dende o século XIX até os 70 . Boletín galego de literatura, n. ${ }^{\circ} 35$, pp. 85-111

- Pons, A.M. (2014) Un retrato de las tipologías sociales de la España de los años 50 a través de EI DDT contra las penas. Espacio, tiempo y forma. Serie V, Historia contemporánea, n. ${ }^{\circ}$ 26, pp. 149-166. Disponible en: http://revistas.uned.es/index. php/ETFV/article/view/14517 [Consulta: 21/04/2021] 